\title{
Management of Acute Lung Injury: Sharing Data Between Adults and Children
}

\author{
Ira M Cheifetz MD FAARC
}

\author{
Introduction \\ Why Are Pediatric Mechanical Ventilation Data Lacking? \\ Pediatric ALI: Learning From Adult Patients \\ Low-Tidal-Volume Ventilation \\ Tidal Volume Measurements \\ PEEP \\ Fluid Management in Acute Lung Injury \\ Corticosteroids for Acute Lung Injury \\ Pediatric and Adult Acute Lung Injury: Synergistic Data \\ Exogenous Surfactant Administration \\ Inhaled Nitric Oxide \\ Adult ARDS: Learning From Pediatric Patients \\ Extracorporeal Membrane Oxygenation \\ High-Frequency Oscillatory Ventilation \\ Summary and Thoughts for the Future
}

\begin{abstract}
As the basis for this paper, it must be acknowledged that children are not simply small adults. But this acknowledgment must go further: infants are not simply small adolescents. As data for pediatric mechanical ventilation, in general, and the management for pediatric acute lung injury, more specifically, are very limited, the pediatric critical care clinician must closely assess the available adult data and evaluate its application for infants and children. Given the hurdles in studying pediatric acute lung injury and acute respiratory distress syndrome, clinicians involved with the care of critically ill infants and children are left with extrapolation of data from the neonatal and adult populations, reliance on the limited available pediatric data, careful assessment of the applicable physiologic and pathophysiologic principles, and/or reliance on their own experience and their colleagues' experience. Hopefully, with the collaboration of multicenter investigator networks, additional and definitive pediatric data may be on the horizon. In the meantime, sharing data between adult and pediatric populations seems to be an essential approach to the management of critically ill patients. Key words: mechanical ventilation; pediatric; acute lung injury; gas exchange; acute respiratory distress syndrome; lung protection; oxygenation; ventilation. [Respir Care 2011;56(9): 1258-1268. (C) 2011 Daedalus Enterprises]
\end{abstract}

Dr Cheifetz is affiliated with the Division of Pediatric Critical Care Medicine, the Pediatric Intensive Care Unit, Pediatric Respiratory Care, and the Extracorporeal Membrane Oxygenation Program, Duke Children's Hospital, Durham, North Carolina.

Dr Cheifetz presented a version of this paper at the 47th RESPIRATORY CARE Journal Conference, "Neonatal and Pediatric Respiratory Care: What Does the Future Hold?" held November 5-7, 2010, in Scottsdale, Arizona.
Dr Cheifetz has disclosed relationships with Philips-Respironics, Covidien, Discovery Laboratories, and Teleflex.

Correspondence: Ira M Cheifetz MD FAARC, Pediatric Critical Care Medicine, Duke Children's Hospital, Duke University Medical Center, Box 3046, Durham NC 27710. E-mail: ira.cheifetz@duke.edu.

DOI: $10.4187 /$ respcare. 01413 


\section{Introduction}

The most common reason for admission to a pediatric intensive care unit (PICU) is the need for mechanical ventilation. Mechanical ventilation occurs on a daily basis for thousands of infants and children around the world. ${ }^{1-4}$ The reasons for mechanical ventilation are varied and include acute respiratory failure due to acute lung injury (ALI)/ acute respiratory distress syndrome (ARDS), chronic respiratory failure due to neuromuscular weakness, acute neurologic abnormalities, airway protection for nonsurgical and surgical procedures, hemodynamic instability with the need to decrease oxygen consumption, and many others. However, definitive, randomized controlled trials to guide the pediatric critical care clinician in his/her ventilatory strategies for an individual infant or child are greatly lacking. Thus, one of the key questions that must be answered is whether data from the adult world can (and should) be extrapolated to infants and children. Conversely, is it reasonable to use pediatric data to guide practice for adult patients? The answer to both sides of the question is probably yes, with some constraints. Given the tremendous breadth of this topic, this paper will focus primarily on therapies/strategies available for the management of pediatric patients with ALI/ARDS. The definition of ALI/ ARDS is based on the 1994 North American-European Consensus Conference and is generally accepted to be the same for infants, children, and adults..$^{5-7}$

As the basis for this discussion, it must be acknowledged that children are not simply small adults. But this acknowledgment must go further: infants are not simply small adolescents. When deciding whether adult data can be safely and accurately extrapolated to pediatrics, one must ask critical questions about the population studied, the effect size, the disease process(es), and the pediatric patient or, more generally, the population in question. A large child or adolescent would clearly mimic the physiology of an adult more closely than would an infant. A primary difficulty for the pediatric practitioner becomes the question of an absolute cutoff age. Unfortunately, there is not a simple answer to this question, and the answer will probably change based on the clinical issue at hand.

\section{Why Are Pediatric Mechanical Ventilation Data Lacking?}

The Pediatric Acute Lung Injury and Sepsis Investigators (PALISI) Network ${ }^{1-4}$ has helped to shed light on the reasons for the lack of definitive pediatric mechanical ventilation data, especially with regard to infants and children with ALI and ARDS. Nine North American PICUs were surveyed for all admissions over a 6-month period. ${ }^{1}$ Of 6,403 total admissions, only $1,096(17.1 \%)$ required mechanical ventilation for greater than 24 hours. Further- more, 701 of these patients met one of the generally accepted exclusions for a prospective clinical trial. These exclusions included limitations of life support, chronic ventilator dependence, chronic neuromuscular weakness, known upper-airway obstruction, hematopoietic stem cell transplantation, uncorrected congenital heart disease, and others. Of the 6,403 total PICU admissions screened over the 6-month period, only 395 (6.2\%) were eligible for a mechanical ventilation weaning study, ${ }^{2}$ and $303(4.7 \%)$ were actually enrolled. It is noteworthy that failure to obtain consent occurred in $23 \%$ of the eligible patients. Furthermore, of the 303 enrolled patients, only 23 were determined to have ARDS, representing $7.6 \%$ of the eligible patients and $0.4 \%$ of the total population screened. The most common diagnoses in this cohort were bronchiolitis $(n=81)$ and pneumonia $(n=48)$.

Whether the standard exclusion criteria used in the PALISI feasibility study ${ }^{1-2}$ are valid has become controversial. Should a prospective clinical trial study the reallife heterogeneous population or a more pure selected group of homogeneous patients? On the one hand, broadening the eligible population will probably increase enrollment, given the relatively small number of potential research subjects. However in doing so, the risk becomes the loss of a real signal in the noise of a more diverse population, and the risk of significant baseline differences in the groups studied. This later problem became apparent in a pediatric surfactant study ${ }^{3}$ in which a larger number of immunocompromised patients were randomly assigned to the placebo group, which eventually had a higher mortality. In such a situation, we are left with uncertainty whether the mortality difference was due to a real intervention effect or to baseline differences in the study groups. Although block randomization may be helpful, it is impossible to predict all potential group differences, and from a statistical viewpoint, the number of block randomized groups must be small.

In a more recent publication, Santschi et al, in collaboration with the PALISI Network and the European Society of Pediatric and Neonatal Intensive Care, ${ }^{4}$ found inconsistent mechanical ventilation strategies for pediatric ALI. Similar to the findings previously described, ${ }^{1}$ this larger-scale follow-up study included 59 PICUs in 12 countries in North America and Europe. Of 3,823 pediatric patients screened on 6 days separated by at least 4 weeks in 2007, $414(10.8 \%)$ were diagnosed with ALI by the clinical care team at the individual centers. However, only $165(4.3 \%)$ of the total patients screened met the preestablished inclusion/exclusion criteria for a clinical trial. Of these 165 pediatric patients, 124 (75.2\%) were conventionally ventilated, 27 (16.4\%) received high-frequency oscillatory ventilation (HFOV), and 14 (8.5\%) were managed with noninvasive ventilation (NIV). Given these small numbers, the researchers concluded that randomized con- 


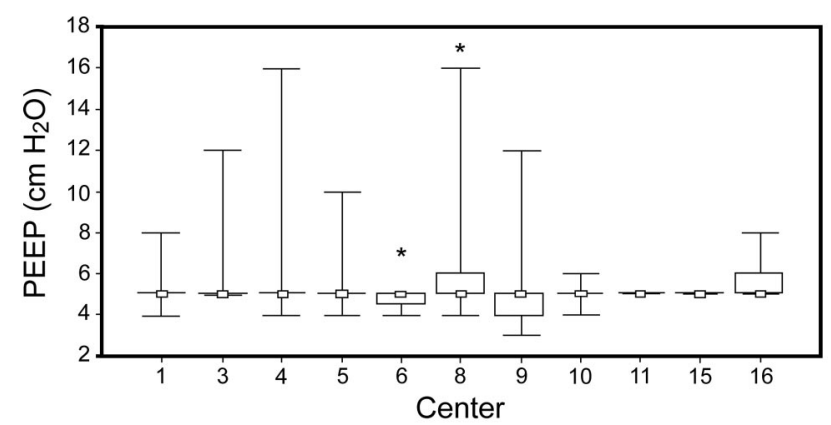

Fig. 1. Variability of PEEP settings in individual pediatric intensive care units. Some centers were willing to vary PEEP on a case by case basis, whereas others rarely altered PEEP. (Adapted from Reference 8, with permission.)

trolled trials in pediatrics would require international participation, with at least 60 centers. The required funding and cooperation would seem overwhelming to most investigators.

Khemani et $\mathrm{al}^{8}$ further defined the difficulties with pediatric mechanical ventilation studies by describing the characteristics of children who were intubated and mechanically ventilated across 16 North American PICUs. There has been substantial variability in the proportion of pediatric patients who are ventilated in various PICUs. This finding may have important implications when choosing PICUs for a clinical investigation. Criteria for intubation, patient populations, use of NIV, and severity of illness would probably become significant confounding variables. This variability may be, in part, due to the presence of step-down/progressive care units in the various pediatric facilities.

As a specific example of the inter-ICU variability seen by Khemani and colleagues, ${ }^{8}$ a pediatric study of PEEP may be very difficult to successfully accomplish. The vast majority of the infants and children were ventilated with a PEEP of $5 \mathrm{~cm} \mathrm{H}_{2} \mathrm{O}$. It is interesting to note that very few infants and children were ventilated with PEEP settings outside of the $4-8 \mathrm{~cm} \mathrm{H}_{2} \mathrm{O}$ range. Reasons for the limited use of higher PEEP settings may include PEEP phobia, the low incidence of severe ALI/ARDS in the pediatric population, and/or the reasonably frequent conversion (as compared to the adult population) to HFOV as an alternative to a higher PEEP strategy. Furthermore, Figure 1 demonstrates the variability of PEEP settings within individual PICUs. Some centers were willing to vary PEEP on a case by case basis, whereas others rarely altered PEEP.

Given these hurdles in studying pediatric ALI and ARDS, clinicians involved with the care of critically ill infants and children are left with extrapolation of data from the neonatal and adult populations, reliance on the limited available pediatric data, careful assessment of the applicable physiologic and pathophysiologic principles, and/or reli- ance on their and their colleagues' experience. As described in more detail below, hopefully, with the collaboration of multicenter investigator networks, additional and definitive pediatric data may be on the horizon.

\section{Pediatric ALI: Learning From Adult Patients}

\section{Low-Tidal-Volume Ventilation}

Current data indicate that limiting lung stretch should be the standard approach for all invasively ventilated adult patients with ALI/ARDS. However, there are insufficient data to prove that a tidal volume $\left(\mathrm{V}_{\mathrm{T}}\right)$ of $6 \mathrm{~mL} / \mathrm{kg}$ (predicted body weight) is the ideal $\mathrm{V}_{\mathrm{T}}$ for all ventilated adult and pediatric patients. Until additional data become available, we must rely on the currently available evidence to guide our clinical practice, so low- $\mathrm{V}_{\mathrm{T}}$ ventilation with $6 \mathrm{~mL} / \mathrm{kg}$ has become a generally accepted management strategy for ALI in adult patients. Many would argue that the only ventilatory intervention to conclusively reduce mortality $(31.0 \%$ vs $39.8 \%, P=.007)$ for adult ALI/ ARDS is low- $\mathrm{V}_{\mathrm{T}}$ (ie, $6 \mathrm{~mL} / \mathrm{kg}$ predicted body weight) ventilation. ${ }^{9}$ In that landmark study, low- $\mathrm{V}_{\mathrm{T}}$ ventilation also increased ventilator-free days and number of days without failure of nonpulmonary organs or systems.

But definitive low- $\mathrm{V}_{\mathrm{T}}$-ventilation data are lacking for infants and children. So for pediatric patients we must extrapolate the data from adult patients and/or rely on our clinical experience and very limited pediatric data. Some may argue that infants and children are different than adults and, thus, these low- $\mathrm{V}_{\mathrm{T}}$ data simply do not apply. However, the counter-argument for pediatric patients with ALI/ ARDS is that the benefits of low- $V_{T}$ ventilation are real, whereas the risks are theoretical. Thus, a majority of pediatric intensivists have adopted low- $\mathrm{V}_{\mathrm{T}}$ ventilation for infants and children with ALI/ARDS.

So, the real question is whether low- $\mathrm{V}_{\mathrm{T}}$ ventilation should be employed for all pediatric (and adult) patients. Should low- $\mathrm{V}_{\mathrm{T}}$ ventilation be used for infants and children with congenital heart disease? What about for children with traumatic brain injury? More generally, what should be the ventilatory approach for any infant or child ventilated for a non-pulmonary reason with baseline normal lungs? We simply do not know the answers to these important questions.

Insights into the pathophysiology of ventilation-induced lung injury resulted from early pre-clinical studies that demonstrated that high- $\mathrm{V}_{\mathrm{T}}$ ventilation resulted in rapid pulmonary changes that mimic ARDS, despite baseline normal lungs. ${ }^{10,11}$ Ventilation settings that resulted in excessive pulmonary stretch led to the development of diffuse alveolar damage, with resultant pulmonary edema, increased inflammatory response, and leakage of these 
immune-modulators into the systemic circulation, with resultant multi-organ dysfunction/failure. ${ }^{12-17}$

Although multiple clinical investigations in adults ventilated with normal lungs ${ }^{18-27}$ have evaluated the effects of low- $\mathrm{V}_{\mathrm{T}}$ versus high- $\mathrm{V}_{\mathrm{T}}$ ventilation, most of those studies had significant intergroup differences in PEEP management and/or primary immune-modulator outcome measurements, of which the clinical correlation is uncertain. A study worth highlighting was by Gajic and colleagues, ${ }^{18}$ who suggested that most (and possibly all) mechanically ventilated adults should be managed with a "low"- $\mathrm{V}_{\mathrm{T}}$ strategy to avoid excessive lung stretch. The percentage of adult patients with previously normal lungs who developed ALI while mechanically ventilated is directly proportional to the size of the delivered $\mathrm{V}_{\mathrm{T}}$. Patients with previously normal lungs who were ventilated with a $\mathrm{V}_{\mathrm{T}}<9 \mathrm{~mL} / \mathrm{kg}$ were much less likely to develop ALI while on mechanical ventilation than those adults who were ventilated with larger $\mathrm{V}_{\mathrm{T}}$. However, it is important to note that the results of this study do not allow us to ascertain whether $\mathrm{V}_{\mathrm{T}}$ less than $9 \mathrm{~mL} / \mathrm{kg}$ is less injurious than $9 \mathrm{~mL} / \mathrm{kg}$. It is unknown whether the less injurious effects of lower- $\mathrm{V}_{\mathrm{T}}$ ventilation are linear below $9 \mathrm{~mL} / \mathrm{kg}$ or if a plateau effect occurs at lower $\mathrm{V}_{\mathrm{T}}$. Unfortunately, additional data are not available to answer this clinically essential question.

Until a definitive randomized controlled trial is available in pediatrics, it would seem reasonable to ventilate infants and children with ALI or ARDS with a $V_{T}$ of $6 \mathrm{~mL} / \mathrm{kg}$ predicted body weight. This recommendation is supported by retrospective pediatric data from Albuali and colleagues, ${ }^{28}$ which indicate that mortality among children with ALI was reduced by $40 \%$ with lower- $\mathrm{V}_{\mathrm{T}}$ ventilation. Two cohorts of patients were studied: those ventilated between 1988 and 1992, and those ventilated between 2000 and 2004. The patients in the earlier period were ventilated with higher $\mathrm{V}_{\mathrm{T}}(10.2 \pm 1.7 \mathrm{~mL} / \mathrm{kg}$ actual body weight vs $8.1 \pm 1.4 \mathrm{~mL} / \mathrm{kg}$ actual body weight, $P<.001)$, lower $\operatorname{PEEP}\left(6.1 \pm 2.7 \mathrm{~cm} \mathrm{H}_{2} \mathrm{O}\right.$ vs $\left.7.1 \pm 2.4 \mathrm{~cm} \mathrm{H}_{2} \mathrm{O}, P=.007\right)$, and higher peak inspiratory pressure $\left(31.5 \pm 7.3 \mathrm{~cm} \mathrm{H}_{2} \mathrm{O}\right.$ vs $\left.27.8 \pm 4.2 \mathrm{~cm} \mathrm{H}_{2} \mathrm{O}, P<.001\right)$. The more recent period had lower mortality ( $21 \%$ vs $35 \%, P=.04)$ and more ventilator-free days $(16.0 \pm 9.0 \mathrm{~d}$ vs $12.6 \pm 9.9 \mathrm{~d}, P=.03)$. Lower $\mathrm{V}_{\mathrm{T}}$ was independently associated with lower mortality and more ventilator-free days, but the study had important limitations, including retrospective design, the measurement of $\mathrm{V}_{\mathrm{T}}$ at the expiratory valve of the ventilator (without consideration of the volume lost due to the distensibility of the ventilator circuit), and the calculation of $\mathrm{V}_{\mathrm{T}}$ based on actual (rather than predicted) body weight.

For pediatric patients with normal lungs, extrapolation from the available adult data would suggest ventilating with a $\mathrm{V}_{\mathrm{T}}$ less than $10 \mathrm{~mL} / \mathrm{kg}$. It should be noted that this recommendation is made upon extrapolation from the adult mechanical ventilation data, as reported by Gajic and colleagues. ${ }^{18}$

The bottom line is that low- $\mathrm{V}_{\mathrm{T}}$ ventilation definitely reduces mortality in adult patients with ALI. Adverse effects have not been reported in that population, and sedation requirements do not significantly increase. Thus, we are left with multiple questions for pediatrics. Can we obtain pediatric low- $\mathrm{V}_{\mathrm{T}}$ data? If so, would the results be different? Would it be ethical to conduct such a study? The ethical question is clearly linked to the proposed study design and populations. Many would have concern about studying $6 \mathrm{~mL} / \mathrm{kg}$ versus $12 \mathrm{~mL} / \mathrm{kg}$, but what about $4 \mathrm{~mL} / \mathrm{kg}$ versus $8 \mathrm{~mL} / \mathrm{kg}$, or $3 \mathrm{~mL} / \mathrm{kg}$ versus $6 \mathrm{~mL} / \mathrm{kg}$ ? Additionally, what should be the age cohorts studied? As an underlying question, is there even equipoise for a low- $\mathrm{V}_{\mathrm{T}}$ ventilation study in pediatrics? Furthermore, what about specialized populations, including congenital heart disease and premature infants? What about infants and children ventilated for conditions other than ALI? Unfortunately, the clinical questions continue to greatly outnumber the available answers. With no definitive studies on the horizon, we remain reliant on extrapolation from the available adult data, in combination with our composite clinical experience and very limited pediatric data.

\section{Tidal Volume Measurements}

One important difference between ventilated pediatric and adult patients must be stressed as a component of any discussion involving $\mathrm{V}_{\mathrm{T}}$ delivery. For adult patients and larger pediatric patients, it is reasonable to measure the delivered $\mathrm{V}_{\mathrm{T}}$ at the expiratory valve of the ventilator, because the volume of gas lost due to the distensibility of the circuit is minimal, as expressed as a percent of the total $\mathrm{V}_{\mathrm{T}}$ delivered. However, for pediatric patients, especially for smaller children and infants, a substantial percentage of the delivered $\mathrm{V}_{\mathrm{T}}$ may be lost due to the distensibility of the ventilator circuit. Cannon et $\mathrm{al}^{29}$ found that for infants ventilated with a neonatal circuit, the expiratory $V_{T}$ measured with a pneumotachometer at the endotracheal tube is on average only $56 \%$ of that measured at the ventilator. Somewhat better correlation was seen in patients ventilated with a pediatric circuit, with the average measured $\mathrm{V}_{\mathrm{T}}$ at the endotracheal tube being $73 \%$ of that measured at the expiratory valve of the ventilator. Similar findings have been reported by Castle et al ${ }^{30}$ and Chow et al. ${ }^{31}$

Thus, when determining the actual delivered $\mathrm{V}_{\mathrm{T}}$ for smaller pediatric patients, placing a pneumotachometer at the endotracheal tube would seem to be the optimal approach. It must be noted that most of the newer generation of mechanical ventilators include software algorithms that estimate the actual delivered $\mathrm{V}_{\mathrm{T}}$ based on calculations using the compliance of the ventilator circuit; however, a review of the medical literature does not provide support 
that those algorithms have been systematically studied for the various devices and algorithms available. Heulitt et al ${ }^{32}$ studied one ventilator type and noted similar findings as previously reported, with the discrepancy between $\mathrm{V}_{\mathrm{T}}$ determinations again being greater for infants and smaller children than for larger patients. This study also noted that the differences in $\mathrm{V}_{\mathrm{T}}$ determination were affected by the use of a ventilator's circuit compensation algorithm. A key potential confounding variable is the potential change in the compliance of the ventilator circuit over time, due to temperature changes, secretions, condensation, and addition of external connectors.

A related topic is the increasing incidence of pediatric obesity. Thus, when determining the appropriate $V_{T}$ for a pediatric patient it is important to use predicted body weight. Although most standard textbooks include ideal body weight calculations for older children, adolescents, and adults, several Internet programs provide interactive calculators to determine the ideal body weight for pediatric patients as young as one year of age. Required inputs are sex, age, and height/length. Alternatively, one may estimate the ideal body weight for a child by using the available sex and age growth charts (http://www.cdc.gov/ growthcharts/clinical_charts.htm). On the appropriate chart, graph the patient's height/length. Once the height/ length percentile is known based on sex and age, simply determine the predicted weight which corresponds to this same percentile.

\section{PEEP}

One of the most frequently discussed topics in the field of mechanical ventilation is PEEP titration. What defines optimal PEEP? What is the best practice for determining the optimal PEEP for an individual patient at a particular point in time? Several large-scale multicenter studies involving adults with ALI have attempted to address these issues. As with low- $\mathrm{V}_{\mathrm{T}}$ ventilation, the data on pediatric patients are very limited.

The ARDS Network's ALVEOLI PEEP trial ${ }^{33}$ by Brower et al, found that mortality was unchanged with the use of a more aggressive PEEP strategy, despite improved arterial oxygenation and improved pulmonary compliance. Several important points about this study should be stressed. First, the lower-PEEP group did not receive "low" PEEP, but, rather, "adequate" PEEP. Second, all of the enrolled patients, regardless of PEEP, were ventilated with a $V_{T}$ of $6 \mathrm{~mL} / \mathrm{kg}$ and an end-inspiratory plateau pressure limit of $30 \mathrm{~cm} \mathrm{H}_{2} \mathrm{O}$. Additionally, there were no safety concerns noted in either of the study groups.

A follow-up study by Meade et $\mathrm{al}^{34}$ also found no survival benefit in adult patients with ALI/ARDS managed with a high-PEEP strategy and recruitment maneuvers, although, again, oxygenation was better. Mercat et al ${ }^{35}$ had a similar survival finding, but they found improved lung function, shorter duration of ventilation, and lower incidence of multi-organ failure with a more aggressive PEEP approach. It should be noted that all patients in the Meade and Mercat studies were also ventilated with a low- $\mathrm{V}_{\mathrm{T}}$ strategy.

In 2010, Briel et al ${ }^{36}$ extracted and combined the data from the Brower, ${ }^{33}$ Meade, ${ }^{34}$ and Mercat ${ }^{35}$ trials, which included 2,299 adult patients with ALI/ARDS. A higherPEEP approach benefited adult patients with ARDS, with shorter duration of ventilation and lower hospital mortality. ${ }^{36}$ This benefit was not seen in patients who did not meet the standard accepted criteria for ARDS, ${ }^{5}$ and the study suggests that elevated PEEP may be associated with longer duration of ventilation in patients with less severe lung injury.

Although the data for adult patients are quite helpful, the pediatric critical care clinician is again left wondering about the best approach for infants and children with ALI/ ARDS. Are the adult PEEP data applicable to infants and children due to their differences in chest wall compliance, cardiac reserve, sedation requirements to tolerate mechanical ventilation, and others? Unfortunately, there is no clear answer to this question. It would seem likely that the adult PEEP data would be applicable to an otherwise normal older child or adolescent, but probably not to an infant with congenital heart disease. Thus, the clinician caring for the pediatric patient must carefully consider the physiology and pathophysiology involved before determining the applicability of the available data from adult ALI and ARDS patients.

In looking to the future, will we be able to obtain definitive PEEP data for infants and children? What PEEP$\mathrm{F}_{\mathrm{IO}_{2}}$ table should be used in the design of a pediatric PEEP trial? Many pediatric clinicians would argue that the PEEP$\mathrm{F}_{\mathrm{IO}_{2}}$ table used in the adult studies ${ }^{33-35}$ would be too aggressive for infants and children. Is this belief simply PEEP phobia or is it realistic given the cardiorespiratory status of infants and children in relation to that of adults? The answer probably lies somewhere in between these possibilities. Given the relatively low mortality in pediatrics, as compared to adults, is mortality a realistic end point, given the limited number of pediatric ARDS patients? It seems unlikely to power a pediatric ARDS-PEEP study on mortality as a primary end point. The most realistic end points for such a study would probably need to be ventilator-free days and organ-failure-free days.

As the most valid PEEP studies in adult patients standardized $\mathrm{V}_{\mathrm{T}}$ in the control and intervention groups at $6 \mathrm{~mL} / \mathrm{kg}$ predicted body weight, would a pediatric low- $\mathrm{V}_{\mathrm{T}}$ study need to occur before a pediatric PEEP study? The questions again become more numerous than the available answers. For now, pediatric critical care clinicians are again left with extrapolating data from the adult population, re- 
lying on individual and institutional experience, and a careful assessment of the specific physiology and pathophysiology involved.

\section{Fluid Management in Acute Lung Injury}

Diuretics are frequently administered in the critical care setting to adult and pediatric patients, for many conditions. The data to support diuretic use in adult patients with ALI/ARDS originate from another ARDS Network randomized controlled trial. ${ }^{37}$ Although no survival benefit was demonstrated between a conservative and a liberal fluid-management strategy, the conservative fluidmanagement approach increased the number of ventilatorfree and ICU-free days. Of importance, an increase in renal failure was not seen in the conservative fluid-management group. Thus, the use of diuretics has become a relatively common approach in this patient population.

Although definitive pediatric fluid management does not exist, a general approach to the infant or child with ALI is similarly to use diuretics with a conservative fluidmanagement strategy in mind. The PALISI Network ${ }^{1,2,38}$ is currently considering such a study. Key issues for a clinical fluid-management investigation include the fluid target(s) (eg, in/out fluid balance, central venous pressure, daily weights). In preliminary work the PALISI network found that cumulative fluid balance for pediatric ICU patients with ALI does not have clinical utility. ${ }^{38}$ Thus, the key to success of such a study will be agreement among the investigators on the liberal and conservative fluidmanagement algorithms, use of invasive monitoring lines, fluid titration end point(s), and outcome measure(s).

Until pediatric data become available, it seems reasonable to extrapolate the general ARDS Network approach to pediatric ALI/ARDS patients and utilize a conservative fluid approach. Unfortunately, the ARDS Network's algorithms ${ }^{37}$ have not been generally applicable to most pediatric populations.

\section{Corticosteroids for Acute Lung Injury}

The use of corticosteroids for ALI/ARDS in both the adult and pediatric populations remains controversial. ${ }^{39}$ The ARDS Network's study ${ }^{40}$ yielded several conclusions. Methylprednisolone was associated with significantly higher 60-day and 180-day mortality in patients enrolled 14 or more days after developing ARDS, whereas mortality was no different in the patients enrolled less than 14 days after ARDS onset. Methylprednisolone increased the number of ventilator-free and shock-free days during the first 28 days (Fig. 2). As compared with placebo, methylprednisolone did not increase the overall rate of infectious complications but was associated with a higher rate of neuromuscular weakness.

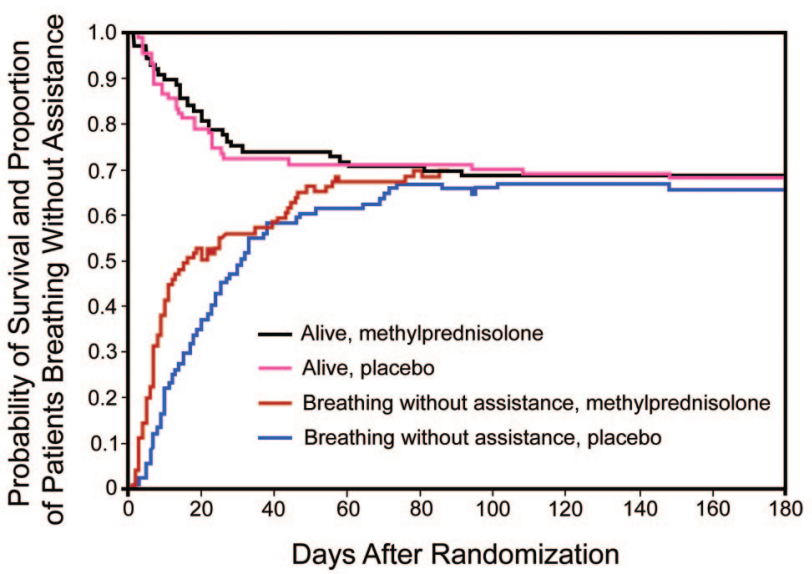

Fig. 2. Corticosteroid therapy for persistent ARDS does not affect survival but does increase ventilator-free days. (Adapted from Reference 40 , with permission.)

In a meta-analysis by Tang et al, ${ }^{41}$ corticosteroids were associated with better survival and less morbidity, without adverse effects. Tang et al concluded that the consistency of the results, in terms of study designs and outcomes, suggests that corticosteroids are an effective treatment for ALI/ARDS. It should be noted that the studies of corticosteroids in the management of adult ALI have methodological limitations, including relatively small sample size. Recommendations differ among experts regarding corticosteroids for late-stage ARDS, although there appears to be a trend toward recommending low-to-moderate-dose corticosteroids for acute lung disease of less than 14 days. It seems reasonable that if corticosteroids are administered, infection surveillance, gradual taper of corticosteroids, and avoidance, if possible, of neuromuscular blockers should occur. ${ }^{39}$

Given the somewhat conflicting results of the ARDS Network ${ }^{40}$ and Tang et al ${ }^{41}$ studies, the extrapolation of these findings to pediatrics is less clear than for low- $\mathrm{V}_{\mathrm{T}}$ ventilation or PEEP titration. Although the use of corticosteroids in the PICU setting seems to be increasing for a variety of critical care disorders, most commonly shock, it must be noted that the use of corticosteroids for pediatric ALI remains at the discretion of the clinician, because definitive data are clearly lacking. Given the more pressing clinical questions of lung-protective ventilation, PEEP titration, and fluid management, it is uncertain if/when the role of corticosteroids for pediatric ALI will reach the top of the list for a multicenter prospective randomized clinical trial.

\section{Pediatric and Adult Acute Lung Injury: Synergistic Data}

Despite the differences between the pediatric and adult populations, there are several adjunct therapies for ALI 
that have yielded similar data. The most commonly discussed (and most controversial) of these approaches are exogenous surfactant administration and inhaled nitric oxide (INO).

\section{Exogenous Surfactant Administration}

Despite the fact that exogenous surfactant administration is a standard of care for infants with neonatal respiratory distress syndrome, ${ }^{42-46}$ its use for pediatric and adult ALI remains debated. Although the preliminary results ${ }^{47-49}$ of surfactant administration for pediatric ALI were promising, more recent studies have been disappointing. ${ }^{3,50,51}$ Similarly disappointing have been the results of surfactant administration in adults. ${ }^{51}$

For adults with ALI/ARDS, exogenous surfactant administration did not improve outcome and showed a trend toward higher mortality and more adverse effects. Kesecioglu and colleagues concluded that at this time exogenous surfactant cannot be recommended for routine use in adult patients with ALI/ARDS, but that alternative exogenous surfactant preparations and/or dosing regimens may prove to be beneficial. ${ }^{51} \mathrm{~A}$ discussion of the various exogenous surfactants at various stages of development and investigation is beyond the scope of this paper. $47,52-58$

Based on both pediatric and adult studies, the use of surfactant for non-neonatal ALI remains uncertain. Although many had hoped that the Calfactant Therapy for Direct Acute Respiratory Distress Syndrome and Direct Acute Lung Injury in Children (CARDS) trial, which involved 30 international centers, would provide definitive guidance for the management of patients with direct lung injury, the study was recently closed for futility in both the pediatric and adult arms. ${ }^{52}$

A more comprehensive discussion of exogenous surfactant use is beyond the focus of this article. For a more detailed review of surfactant use in the PICU setting as well as for speculations about the future of this potential therapy, please see Willson and Notter's paper in this issue. ${ }^{52}$

\section{Inhaled Nitric Oxide}

INO plays an important role in the management of infants with persistent pulmonary hypertension of the newborn, older children and adults with pulmonary hypertension, and a subset of patients with congenital heart disease. However, despite several studies in both pediatric and adult patients that found clear improvements in oxygenation with INO therapy, ${ }^{59-62}$ improvements in measurable outcomes have not been demonstrated. ${ }^{61-64}$ Many have hypothesized that INO should benefit patients with ALI by improving oxygenation and thus allowing the clinician to wean ventilatory support and minimize the occurrence of ventilator- induced lung injury. Unfortunately, this theory has never been proven correct.

In a meta-analysis of 14 randomized controlled trials with a total of 1,303 participants, INO showed no statistically significant effect on mortality. ${ }^{63,64}$ Studies have failed to demonstrate a statistically significant effect of INO on mortality, duration of ventilation, ventilator-free days, ICU stay, or hospital stay. Of interest, INO may increase the risk of renal impairment in adults. ${ }^{63}$ Afshari et al ${ }^{63,64}$ concluded that INO cannot be recommended for patients with acute hypoxemic respiratory failure. INO transiently improves oxygenation but does not reduce mortality and may be harmful. ${ }^{63,64}$ Based on the currently available data, this conclusion seems applicable to both children and adults with ALI/ARDS, in the absence of clinically important pulmonary hypertension.

\section{Adult ARDS: Learning From Pediatric Patients}

\section{Extracorporeal Membrane Oxygenation}

Extracorporeal membrane oxygenation (ECMO) is one therapy on which there are substantially more data from infants and children than from adults. ECMO involves an extracorporeal circuit with a pump and an oxygenator, to support life in the case of refractory cardiac and/or respiratory failure. In venoarterial ECMO, both the heart and lungs are bypassed to provide cardiac and/or respiratory support. In venovenous ECMO, the ECMO system serves as an additional lung to augment gas exchange, thus allowing the ventilator settings to be set below (ideally, substantially below) toxic levels. With venoarterial or venovenous ECMO the clinician must remember that ECMO does not heal or treat the underlying problems but rather provides cardiac and/or respiratory support to allow the underlying processes to resolve without the need for toxic ventilator or vasoactive agent/inotrope support. Please see Dalton's paper in this issue for a more comprehensive discussion of ECMO. ${ }^{65}$

Although the initial (and successful) use of ECMO occurred in an adult trauma patient, this life-saving technology became a standard approach for refractory cardiorespiratory failure in the neonatal and, subsequently, pediatric populations long before being established as a potential therapy for adults. ${ }^{66-73}$ Of the 44,824 patients who have been reported to the Extracorporeal Life Support Organization from the late 1980s through December 2010, 65.2\% have been neonates, $25.0 \%$ have been pediatric patients, and $9.8 \%$ have been adults. ${ }^{74}$ For those patients requiring respiratory support, survival is clearly better for neonates (75\%) than for pediatric patients $(56 \%)$ or adults $(54 \%)$ (Table 1). It is interesting to note the very similar ECMO survival rates for pediatric and adult patients requiring respiratory support. 
Table 1. Numbers and Outcomes of Neonatal, Pediatric, and Adult ECMO Patients, as of December 2010

\begin{tabular}{|c|c|c|c|}
\hline & $\begin{array}{c}\text { Number of } \\
\text { Patients }\end{array}$ & $\begin{array}{l}\text { Survived } \\
\text { ECMO } \\
\text { no. }(\%)\end{array}$ & $\begin{array}{c}\text { Survived } \\
\text { to Discharge } \\
\text { or Transfer } \\
\text { no. }(\%)\end{array}$ \\
\hline \multicolumn{4}{|l|}{ Neonatal } \\
\hline Respiratory & 24,344 & $20,608(85)$ & $18,276(75)$ \\
\hline Cardiac & 4,232 & $2,566(61)$ & $1,663(39)$ \\
\hline ECPR & 640 & 403 (63) & $245(38)$ \\
\hline \multicolumn{4}{|l|}{ Pediatric } \\
\hline Respiratory & 4,771 & $3,094(65)$ & $2,656(56)$ \\
\hline Cardiac & 5,221 & $3,322(64)$ & $2,502(48)$ \\
\hline ECPR & 1,220 & $646(53)$ & 479 (39) \\
\hline \multicolumn{4}{|l|}{ Adult } \\
\hline Respiratory & 2,340 & $1,474(63)$ & $1,261(54)$ \\
\hline Cardiac & 1,540 & $812(53)$ & 598 (39) \\
\hline ECPR & 516 & 201 (39) & $153(30)$ \\
\hline Totals & 44,824 & $33,126(74)$ & $27,833(62)$ \\
\hline \multicolumn{4}{|c|}{$\begin{array}{l}\text { ECMO }=\text { extracorporeal membrane oxygenation } \\
\text { ECPR }=\text { extracorporeal cardiopulmonary resuscitation } \\
\text { (From Reference } 74 \text { with permission.) }\end{array}$} \\
\hline
\end{tabular}

Although ECMO support for refractory hypoxemia has become routine for neonates, infants, and children, the extrapolation of this experience to adults has increased only in recent years. The H1N1 experience 72,75 and the positive results of the European Conventional Ventilation or ECMO For Severe Adult Respiratory Failure (CESAR) trial for refractory ARDS emphasize the potential benefits of ECMO in adults. ECMO highlights an important area in which neonatal and pediatric critical care clinicians can share not only data but also important experience with our adult colleagues.

\section{High-Frequency Oscillatory Ventilation}

HFOV is another management strategy for ALI/ARDS that has expanded from pediatrics to adults. Despite the lack of a definitive, randomized controlled trial in pediatric patients to demonstrate an advantage of HFOV over a conventional-ventilation, low- $\mathrm{V}_{\mathrm{T}}$ strategy, the use of HFOV in infants and children has become routine. ${ }^{76-78}$ The one randomized controlled trial of HFOV and conventional ventilation was reported back in 1994 by Arnold et al, and it should be stressed that the control group received a high- $\mathrm{V}_{\mathrm{T}}$ approach. ${ }^{79}$

In the adult population, HFOV has been demonstrated to be equivalent to lung-protective, conventional ventilation, and its use has steadily increased. ${ }^{80-82}$ However, despite the available data and increasing use, HFOV for adult ALI/ARDS remains controversial, and this controversy is well described in Fessler and Hess's paper from a prior Journal Conference. ${ }^{83}$
The question of whether definitive data showing the superiority of HFOV over conventional ventilation will be obtained for children or adults remains uncertain. With the widespread use of HFOV in pediatrics, it seems unlikely that such a study will be performed, as equipoise may be lacking, especially in centers that routinely use HFOV. Without those, generally larger, centers there may be an inadequate available population for such a study. It also remains uncertain whether the ARDS Network will embark on such a study in the adult population. In the meantime, it is worthwhile to mention a meta-analysis published in the British Medical Journal last year ${ }^{84}$ that concluded that HFOV "might improve survival and is unlikely to cause harm." Unfortunately, that may be the best summary we will have on HFOV for pediatric or adult ALI/ARDS for some time to come.

\section{Summary and Thoughts for the Future}

Prospective randomized controlled trials on pediatric ALI and ARDS are needed. In the absence of definitive data, pediatric critical care clinicians are left with extrapolation of data from the neonatal and adult populations, reliance on their and their colleagues' clinical experience, and the clinical application of the pertinent physiology and pathophysiology. As the available data, clinical experience, and knowledge of the physiology/pathophysiology are extrapolated to a specific patient, one must remember carefully to consider the numerous uncontrolled variables in the "real life" critical care setting, including the knowledge and experience of the respiratory therapists, physicians, nurse practitioners, bedside nurses, ECMO specialists, pharmacists, and the other personnel in that ICU team.

Until definitive data are obtained to answer the many clinical questions posed in this article in regard to the pediatric population, we must remember that often more data are required to determine the efficacy of a therapy than its safety. Thus, one must consider the frequently debated question, if an approach has been demonstrated to be safe but is unknown to conclusively improve outcome, is it reasonable to proceed? In a paper from a prior Journal Conference, Rubin and Steinberg ${ }^{85}$ concluded that:

Physicians are morally obligated to provide the best and most appropriate care possible for their patients, but when accepted approaches are failing and a critically ill patient is getting worse, the critical care physician must make a decision regarding innovative therapy, based on the patient's prognosis, the available evidence, the resources on hand, the expertise of the physicians, and the values of the patient and the physician. This decision may lead, at times, to trying unproven and innovative strategies to achieve a clinical goal. In such cases, it is to be hoped that this can be done in such a way that data 


\section{Management of Acute Lung Injury: Sharing Data Between Adults and Children}

are formally and prospectively collected to increase our knowledge.

One should remain hopeful that more definitive pediatric data are forthcoming, especially with the cooperative efforts and recent growth of the PALISI Network, ${ }^{1-3,38}$ the Collaborative Pediatric Critical Care Research Network, ${ }^{86-89}$ the Australian and New Zealand Intensive Care Society Clinical Trials Group, ${ }^{6,90,91}$ and other multicenter collaborations. We look forward to more definitive data to guide pediatric critical care clinicians in their management of infants and children with ALI and ARDS are on the horizon.

\section{REFERENCES}

1. Randolph AG, Meert KL, O'Neil ME, Hanson JH, Luckett PM, Arnold JH, et al; Pediatric Acute Lung Injury and Sepsis Investigators (PALISI) Network. The feasibility of conducting clinical trials in infants and children with acute respiratory failure. Am J Respir Crit Care Med 2003;167(10):1334-1340.

2. Randolph AG, Wypij D, Venkataraman ST, Hanson JH, Gedeit RG, Meert KL, et al; Pediatric Acute Lung Injury and Sepsis Investigators (PALISI) Network. Effect of mechanical ventilator weaning protocols on respiratory outcomes in infants and children: a randomized controlled trial. JAMA 2002;288(20):2561-2568.

3. Willson DF, Thomas NJ, Markovitz BP, Bauman LA, DiCarlo JV, Pon S, et al; Pediatric Acute Lung Injury and Sepsis Investigators (PALISI) Network. Effect of exogenous surfactant (calfactant) in pediatric acute lung injury: a randomized controlled trial. JAMA 2005;293(4):470-476.

4. Santschi M, Jouvet P, Leclerc F, Gauvin F, Newth CJ, Carroll CL, et al; PALIVE Investigators; Pediatric Acute Lung Injury and Sepsis Investigators Network (PALISI) and the European Society of Pediatric and Neonatal Intensive Care (ESPNIC). Acute lung injury in children: therapeutic practice and feasibility of international clinical trials. Pediatr Crit Care Med 2010;11(6):681-689.

5. Bernard GR, Artigas A, Brigham KL, Carlet J, Falke K, Hudson L, et al. The North American-European Consensus Conference on ARDS: definitions, mechanisms, relevant outcomes, and clinical trial coordination. Am J Respir Crit Care Med 1994;149(3):818-824.

6. Erickson S, Schibler A, Numa A, Nuthall G, Yung M, Pascoe E, et al. Acute lung injury in pediatric intensive care in Australia and New Zealand: a prospective, multicenter, observational study. Pediatr Crit Care Med 2007;8(4):317-323.

7. Zimmerman JJ, Akhtar SR, Caldwell E, Rubenfeld GD. Incidence and outcomes of pediatric acute lung injury. Pediatrics 2009;124(1): 87-95.

8. Khemani RG, Markovitz BP, Curley MAQ. Characteristics of children Intubated and mechanically ventilated in 16 PICUs. Chest 2009; 136(3):765-771

9. The Acute Respiratory Distress Syndrome Network. Ventilation with lower tidal volumes as compared with traditional tidal volumes for acute lung injury and the acute respiratory distress syndrome. $\mathrm{N}$ Engl J Med 2000;342(18):1301-1308.

10. Villar J. Ventilator or physician-induced lung injury? Minerva Anestesiol 2005;71(6):255-258.

11. Dreyfuss D, Saumon G. Ventilator-induced lung injury: Lessons from experimental studies. Am J Respir Crit Care Med 1998;157(1): 294-323.
12. Kawano T, Mori S, Cybulsky M, Burger R, Ballin A, Cutz E, Bryan AC. Effect of granulocyte depletion in a ventilated surfactantdepleted lung. J Appl Physiol 1987;62(1):27-33.

13. Sugiura M, McCulloch PR, Wren S, Dawson RH, Froese AB. Ventilator pattern influences neutrophil influx and activation in atelectasis-prone rabbit lung. J Appl Physiol 1994;77(3):1355-1365.

14. Ricard JD, Dreyfuss D, Saumon G. Production of inflammatory cytokines in ventilator-induced lung injury: a reappraisal. Am J Respir Crit Care Med 2001;163(5):1176-1180

15. Tremblay L, Valenza F, Ribeiro SP, Li J, Slutsky AS. Injurious ventilatory strategies increase cytokines and c-fos m-RNA expression in an isolated rat lung model. J Clin Invest 1997;99(5):944-952.

16. Haitsma JJ, Uhlig S, Goggel R, Verbrugge SJ, Lachmann U, Lachmann B. Ventilator-induced lung injury leads to loss of alveolar and systemic compartmentalization of tumor necrosis factor-alpha. Intensive Care Med 2000;26(10):1515-1522.

17. Haitsma JJ, Uhlig S, Lachmann U, Verbrugge SJ, Poelma DL, Lachmann B. Exogenous surfactant reduces ventilator-induced decompartmentalization of tumor necrosis factor alpha in absence of positive end-expiratory pressure. Intensive Care Med 2002;28(8):11311137.

18. Gajic O, Dara SI, Mendez JL, Adesanya AO, Festic E, Caples SM, et al. Ventilator-associated lung injury in patients without acute lung injury at the onset of mechanical ventilation. Crit Care Med 2004; 32(9):1817-1824.

19. Michelet P, D'Journo XB, Roch A, Doddoli C, Marin V, Papazian L, et al. Protective ventilation influences systemic inflammation after esophagectomy: a randomized controlled study. Anesthesiology 2006; 105(5):911-919.

20. Lee PC, Helsmoortel CM, Cohn SM, Fink MP. Are low tidal volumes safe? Chest 1990;97(2):430-434.

21. Wrigge H, Zinserling J, Stuber F, von Spiegel T, Hering R, Wetegrove $\mathrm{S}$, et al. Effects of mechanical ventilation on release of cytokines into systemic circulation in patients with normal pulmonary function. Anesthesiology 2000;93(6):1413-1417.

22. Koner O, Celebi S, Balci H, Cetin G, Karaoglu K, Cakar N. Effects of protective and conventional mechanical ventilation on pulmonary function and systemic cytokine release after cardiopulmonary bypass. Intensive Care Med 2004;30(4):620-626.

23. Wrigge H, Uhlig U, Zinserling J, Behrends-Callsen E, Ottersbach G, et al. The effects of different ventilatory settings on pulmonary and systemic inflammatory responses during major surgery. Anesth Analg 2004;98(3):775-781.

24. Wrigge H, Uhlig U, Baumgarten G, Menzenbach J, Zinserling J, Ernst M, et al. Mechanical ventilation strategies and inflammatory responses to cardiac surgery: a prospective randomized clinical trial. Intensive Care Med 2005;31(10):1379-1387.

25. Zupancich E, Paparella D, Turani F, Munch C, Rossi A, Massaccesi $\mathrm{S}$, Ranieri VM. Mechanical ventilation affects inflammatory mediators in patients undergoing cardiopulmonary bypass for cardiac surgery: a randomized clinical trial. J Thorac Cardiovasc Surg 2005; 130(2):378-383.

26. Reis Miranda D, Gommers D, Struijs A, Dekker R, Mekel J, Feelders $\mathrm{R}$, et al. Ventilation according to the open lung concept attenuates pulmonary inflammatory response in cardiac surgery. Eur J Cardiothorac Surg 2005;28(6):889-895.

27. Choi G, Wolthuis EK, Bresser P, Levi M, van der Poll T, Dzoljic M, et al. Mechanical ventilation with lower tidal volumes and positive end-expiratory pressure prevents alveolar coagulation in patients without lung injury. Anesthesiology 2006;105(4):689-695.

28. Albuali WH, Singh RN, Fraser DD, Seabrook JA, Kavanagh BP, Parshuram CS, Kornecki A. Have changes in ventilation practice improved outcome in children with acute lung injury? Pediatr Crit Care Med 2007;8(4):324-330. 


\section{Management of Acute Lung Injury: Sharing Data Between Adults and Children}

29. Cannon ML, Cornell J, Tripp DS, Gentile MA, Hubble CL, Meliones JN, Cheifetz IM. Tidal volumes for ventilated infants should be determined with a pneumotachometer placed at the endotracheal tube. Am J Respir Crit Care Med 2000;162(6):2109-2112.

30. Castle RA, Dunne CJ, Mok Q, Wade AM, Stocks J. Accuracy of displayed tidal volume in the pediatric intensive care unit. Crit Care Med 2002;39(11):2566-2574.

31. Chow LC, Vanderhal A, Raber J, Sola A. Are tidal volume measurements in neonatal pressure-controlled ventilation accurate? Pediatr Pulmonol 2002;34(3):196-202.

32. Heulitt MJ, Thurman TL, Holt SJ, Jo CH, Simpson P. Reliability of displayed tidal volume in infants and children during dual-controlled ventilation. Pediatr Crit Care Med 2009;10(6):661-667.

33. Brower RG, Lanken PN, MacIntyre N, Matthay MA, Morris A, Ancukiewicz M, Schoenfeld D, Thompson BUT; National Heart, Lung, and Blood Institute ARDS Clinical Trials Network. Higher versus lower positive end-expiratory pressures in patients with the acute respiratory distress syndrome. N Engl J Med 2004;351(4):327336.

34. Meade MO, Cook DJ, Guyatt GH, Slutsky AS, Arabi YM, Cooper DJ, et al. Ventilation strategy using low tidal volumes, recruitment maneuvers, and high positive end-expiratory pressure for acute lung injury and acute respiratory distress syndrome. JAMA 2008;299(6): 637-645.

35. Mercat A Richard JC, Vielle B, Jaber S, Osman D, Diehl JL, et al. on behalf of the Expiratory Pressure (Express) Study Group. Positive end-expiratory pressure setting in adults with acute lung injury and acute respiratory distress syndrome: a randomized controlled trial. JAMA 2008;299(6):646-655.

36. Briel M, Meade M, Mercat A, Brower RG, Talmor D, Walter SD, et al. Higher vs. lower positive end-expiratory pressure in patients with acute lung injury and acute respiratory distress syndrome: systematic review and meta-analysis. JAMA 2010;303(9):865-873.

37. Wiedemann HP, Wheeler AP, Bernard GR, Thompson BT, Hayden D, deBoisblanc B, et al; National Heart, Lung, and Blood Institute Acute Respiratory Distress Syndrome (ARDS) Clinical Trials Network Comparison of two fluid management strategies in acute lung injury N Engl J Med 2006;354(24):2564-2575.

38. Randolph AG, Forbes PW, Gedeit RG, Arnold JH, Wetzel RC, Luckett $\mathrm{PM}$, et al; Pediatric Acute Lung Injury and Sepsis Investigators (PALISI) Network. Cumulative fluid intake minus output is not associated with ventilator weaning duration or extubation outcomes in children. Pediatr Crit Care Med 2005;6(6):642-647.

39. Sessler CN, Gay PC. Are corticosteroids useful in late-stage acute respiratory distress syndrome? Respir Care 2010;55(1):43-52.

40. Steinberg KP, Hudson LD, Goodman RB, Hough CL, Lanken PN, Hyzy R, et al; National Heart, Lung, and Blood Institute Acute Respiratory Distress Syndrome (ARDS) Clinical Trials Network. Efficacy and safety of corticosteroids for persistent acute respiratory distress syndrome. N Engl J Med 2006;354(16):1671-1684.

41. Tang BMP, Craig JC, Eslick GD, Seppelt I, McLean AS. Use of corticosteroids in acute lung injury and acute respiratory distress syndrome: A systematic review and meta-analysis. Crit Care Med 2009;37(5):1594-1603.

42. Jobe AH. Pulmonary surfactant therapy. N Engl J Med 1993;328(12): 861-868.

43. Soll RF. Surfactant therapy in the USA: Trials and current routines. Biol Neonate 1997;71(Suppl 1):1-7.

44. Findlay RD, Taeusch HW, Walther FJ. Surfactant replacement therapy for meconium aspiration syndrome. Pediatrics 1996;97(1):48-52.

45. Lotze A, Knight GR, Martin GR, Bulas DI, Hull WM, O'Donnell $\mathrm{RM}$, et al. Improved pulmonary outcome after exogenous surfactant therapy for respiratory failure in term infants requiring extracorporeal membrane oxygenation. J Pediatr 1993;122(2):261-268.
46. Lotze A, Mitchell BR, Bulas DI, Zola EM, Shalwitz RA, Gunkel JH Multicenter study of surfactant (beractant) use in the treatment of term infants with severe respiratory failure. J Pediatr 1998;132(1): 40-47.

47. Willson DF, Chess PR, Notter RH. Surfactant for pediatric acute lung injury. Pediatr Clin North Am 2008;55(3):545-575.

48. Willson DF, Zaritsky A, Bauman LA, Dockery K, James RL, Conrad $\mathrm{D}$, et al. Instillation of calf lung surfactant extract (calfactant) is beneficial in pediatric acute hypoxemic respiratory failure. Members of the Mid-Atlantic Pediatric Critical Care Network. Crit Care Med 1999;27(1):188-195.

49. Willson DF, Jiao JH, Bauman LA, Zaritsky A, Craft H, Dockery K, et al. Calf's lung surfactant extract in acute hypoxemic respiratory failure in children. Crit Care Med 1996;24(8):1316-1322.

50. Czaja AS. A critical appraisal of a randomized controlled trial: Willson et al: Effect of exogenous surfactant (calfactant) in pediatric acute lung injury (JAMA 2005, 293: 470-476). Pediatr Crit Care Med 2007;8(1):50-53

51. Kesecioglu J, Beale R, Stewart TE, Findlay GP, Rouby JJ, Holzapfel $\mathrm{L}$, et al. Exogenous natural surfactant for treatment of acute lung injury and the acute respiratory distress syndrome. Am J Respir Crit Care Med 2009;180(10):989-994

52. Willson DF, Notter RH. The future of exogenous surfactant therapy. Respir Care 2011;56(9):1369-1386; discussion 1386-1388.

53. Willson DF, Chess PR, Wang Z, Notter RH. Pulmonary surfactant: biology and therapy. In: Wheeler DA WH, Shanley TA, ed. Pediatric Critical Care Medicine: Basic Science and Clinical Evidence. London: Springer-Verlag; 2007:453-466.

54. Raghavendran K, Pryhuber GS, Chess PR, B.A. D, Knight PR, Notter RH. Pharmacotherapy of acute lung injury and acute respiratory distress syndrome. Curr Med Chem 2008;15(19):1911-1924

55. Notter RH, Schwan AL, Wang Z, Waring AJ. Novel phospholipaseresistant lipid/peptide synthetic lung surfactants. Mini-Rev Med Chem 2007;7(9):932-944.

56. Walther FJ, Waring AJ, Sherman MA, Zasadzinski J, Gordon LM. Hydrophobic surfactant proteins and their analogues. Neonatology 2007;91(4):303-310.

57. Wang Z, Chang Y, Schwan AL, Notter RH. Activity and inhibition resistance of a phospholipaseresistant synthetic exogenous surfactant in excised rat lungs. Am J Respir Cell Mol Biol 2007;37(4):387-394.

58. Mingarro I, Lukovic D, Vilar M, Pérez-Gil J. Synthetic pulmonary surfactant preparations: New developments and future trends. Current Med Chem 2008;15(4):303-403.

59. Gerlach H, Keh D, Semmerow A, Busch T, Lewandowski K, Pappert $\mathrm{DM}$, et al. Dose response characteristics during long-term inhalation of nitric oxide in patients with severe acute respiratory distress syndrome: a prospective, randomized, controlled study. Am J Respir Crit Care Med 2003;167(7):1008-1015.

60. Dellinger RP, Zimmerman JL, Taylor RW, Straube RC, Hauser DL, Criner GJ, et al; Inhaled Nitric Oxide in ARDS Study Group. Effects of inhaled nitric oxide in patients with acute respiratory distress syndrome: results of a randomized phase II trial. Crit Care Med 1998;26(1):15-23.

61. Taylor RW, Zimmerman JL, Dellinger RP, Straube RC, Criner GJ, Davis K Jr, et al; Inhaled Nitric Oxide in ARDS Study Group. Low-dose inhaled nitric oxide in patients with acute lung injury: a randomized controlled trial. JAMA 2004;291(13):1603-1609.

62. Adhikari NK, Burns KE, Friedrich JO, Granton JT, Cook DJ, Meade MO. Effect of nitric oxide on oxygenation and mortality in acute lung injury: systematic review and meta-analysis. BMJ 2007; 334(7597): 779.

63. Afshari A, Brok J, Møller AM, Wetterslev J. Inhaled nitric oxide for acute respiratory distress syndrome and acute lung injury in adults 
and children: a systematic review with Meta-analysis and trial sequential analysis. Anesth Analg 2011. [epub ahead of print].

64. Afshari A, Brok J, Moller AM, Wetterslev J. Inhaled nitric oxide for acute respiratory distress syndrome (ARDS) and acute lung injury in children and adults. Cochrane Database Syst Rev 2010;(7):CD002787.

65. Dalton HJ. Extracorporeal life support: moving at the speed of light. Respir Care 2011;56(9):1445-1453; discussion 1454-1456.

66. Hill JD, De Leval MR, Fallat RJ, Bramson ML, Eberhart RC, Schulte $\mathrm{HD}$, et al. Acute respiratory insufficiency. Treatment with prolonged extracorporeal oxygenation. J Thorac Cardiovasc Surg 1972;64(4): 551-562.

67. Hill JD, O’Brien TG, Murray JJ, Dontigny L, Bramson ML, Osborn JJ, Gerbode F. Prolonged extracorporeal oxygenation for acute posttraumatic respiratory failure (shock-lung syndrome). Use of the Bramson membrane lung. N Engl J Med 1972;286(12):629-634.

68. Bartlett RH, Roloff DW, Cornell RG, Andrews AF, Dillon PW, Zwischenberger JB. Extracorporeal circulation in neonatal respiratory failure: a prospective randomized study. Pediatrics 1985;76(4): 479-487.

69. Hocker JR, Simpson PM, Rabalais GP, Stewart DL, Cook LN. Extracorporeal membrane oxygenation and early-onset group B streptococcal sepsis. Pediatrics 1992;89(1):1-4.

70. Kanto WP Jr. A decade of experience with neonatal extracorporeal membrane oxygenation. J Pediatr 1994;124(3):335-347.

71. Moler FW, Custer JR, Bartlett RH, Palmisano JM, Akingbola O, Taylor RP, Maxvold NJ. Extracorporeal life support for severe pediatric respiratory failure: an updated experience 1991-1993 J Pediatr. 1994;124(6):875-880.

72. The Australia and New Zealand Extracorporeal Membrane Oxygenation (ANZ ECMO) Influenza Investigators. Extracorporeal membrane oxygenation for 2009 influenza A(H1N1) acute respiratory distress syndrome. JAMA 2009;302(17):1888-1895.

73. Peek GJ, Mugford M, Tiruvoipati R, Wilson A, Allen E, Thalanany $\mathrm{MM}$, et al; CESAR trial collaboration. Efficacy and economic assessment of conventional ventilatory support versus extracorporeal membrane oxygenation for severe adult respiratory failure (CESAR): a multicentre randomised controlled trial. Lancet 2009;374(9698): 1351-1363.

74. Extracorporeal Life Support Organization (ELSO) Database. January, 2011. http://www.elso.med.umich.edu/Default.htm. Accessed July 7, 2011.

75. Turner DA, Rehder KJ, Peterson-Carmichael SL, Ozment CP, AlHegelan MS, Williford WL, et al. Extracorporeal membrane oxygenation for severe refractory respiratory failure secondary to 2009 H1N1 influenza A. Respir Care 2011;56(7):941-946.

76. Ten IS, Anderson MR. Is high-frequency ventilation more beneficial than low-tidal volume conventional ventilation? Respir Care Clin N Am 2006;12(3):437-451.

77. Ventre KM, Arnold JH. High frequency oscillatory ventilation in acute respiratory failure. Paediatr Respir Rev 2004;5(4):323-332.

78. Arnold JH, Anas NG, Luckett P, Cheifetz IM, Reyes G, Newth CJ, et al. High-frequency oscillatory ventilation in pediatric respiratory failure: a multicenter experience. Crit Care Med 2000;28(12):39133919.
79. Arnold JH, Hanson JH, Toro-Figuero LO, Gutiérrez J, Berens RJ, Anglin DL. Prospective, randomized comparison of high-frequency oscillatory ventilation and conventional mechanical ventilation in pediatric respiratory failure. Crit Care Med 1994;22(10):1530-1539.

80. Chan KP, Stewart TE, Mehta S. High-frequency oscillatory ventilation for adult patients with ARDS. Chest 2007;131(6):1907-1916.

81. Derdak S, Mehta S, Stewart TE, Smith T, Rogers M, Buchman TG, et al; Multicenter Oscillatory Ventilation for Acute Respiratory Distress Syndrome Trial (MOAT) Study Investigators. High frequency oscillatory ventilation for acute respiratory distress syndrome: A randomized, controlled trial. Am J Respir Crit Care Med 2002;166(6): 801-808.

82. Derdak S, High-frequency oscillatory ventilation for acute respiratory distress syndrome in adult patients. Crit Care Med 2003;31(4; Suppl):S317-323.

83. Fessler HE, Hess DR. Respiratory controversies in the critical care setting. Does high-frequency ventilation offer benefits over conventional ventilation in adult patients with acute respiratory distress syndrome? Respir Care 2007;52(5):595-605, discussion 606-608.

84. Sud S, Sud M, Friedrich JO, Meade MO, Ferguson ND, Wunsch H, Adhikari NK. High frequency oscillation in patients with acute lung injury and acute respiratory distress syndrome (ARDS): Systematic review and meta-analysis. BMJ 2010;340:c2327.

85. Rubin BK, Steinberg KP. When caring for critically ill Patients, do clinicians have a responsibility to be innovative and try unproven approaches when accepted approaches are failing? Respir Care 2007; 52(4):408-413; discussion 413-415.

86. Burr JS, Jenkins TL, Harrison R, Meert K, Anand KJ, Berger JT, et al; Eunice Kennedy Shriver National Institute of Child Health and Human Development (NICHD) Collaborative Pediatric Critical Care Research Network (CPCCRN). The Collaborative Pediatric Critical Care Research Network (CPCCRN) Critical Pertussis Study: collaborative research in pediatric critical care medicine. Pediatr Crit Care Med 2011;12(4):387-392.

87. Meert KL, Eggly S, Dean JM, Pollack M, Zimmerman J, Anand KJ, et al. Ethical and logistical considerations of multicenter parental bereavement research. J Palliat Med 2008;11(3):444-450.

88. Meert KL, Eggly S, Pollack M, Anand KJ, Zimmerman J, Carcillo J, et al; National Institute of Child Health and Human Development Collaborative Pediatric Critical Care Research Network. Parents' perspectives regarding a physician-parent conference after their child's death in the pediatric intensive care unit. J Pediatr 2007; 151(1):50-55.

89. Willson DF, Dean JM, Newth C, Pollack M, Anand KJ, Meert K, et al; Collaborative Pediatric Critical Care Research Network (CPCCRN). Pediatr Crit Care Med 2006;7(4):301-307.

90. Yung M, Slater A, Festa M, Williams G, Erickson S, Pettila V, et al; Australia and New Zealand Intensive Care Influenza Investigators and the Paediatric Study Group and the Clinical Trials Group of the Australia New Zealand Intensive Care Society. Pandemic H1N1 in children requiring intensive care in Australia and New Zealand during winter 2009. Pediatrics 2011;127(1):e156-163.

91. The ANZIC Influenza Investigators. Critical care services and 2009 H1N1 influenza in Australia and New Zealand. N Engl J Med 2009; 361(20):1925-1934.

\section{Discussion}

Fineman: In terms of outcomes in younger kids, obviously mortality is not very high, but are ventilator-days really that important? Should we be looking more at longer-term functional outcomes? Are those easy to do?

Cheifetz: We cannot target mortality in an ALI/ARDS study, because the mortality is too low to significantly change with a single-intervention study. I believe ventilator-free days and ICU-free days are reasonable end points. If a patient is going to survive, we all know that every family, every patient, everyone wants this to occur 
as quickly as possible. Also, from the viewpoint of resource utilization, ICU days and ventilator days are important.

Your second question raises a very important point. We have not done a good job of determining neurologic and pulmonary function at 6 months, 12 months, and beyond. Most would agree that it is acceptable to be on a ventilator in the ICU for 5 additional days if that provides a better functional outcome at 6 or 12 months. But we have no data, and it is an important point that we need to consider as we design future studies.

Fineman: Everyone talks about whether adults and kids should be put in the same trial, but what about an 8-month-old and a 14-year-old?

Cheifetz: That is a key point. Though children are not simply small adults, there $i s$ an age at which the physiology becomes sufficiently similar that we can combine older children and adults. Most would agree that an 8-month-old and a 14-year-old are very different. The FDA has used an age cutoff of 12 years for including pediatric patients in adult studies. I think that's reasonable, but I do not know what the cutoff should really be. Is it really 12 years? Should it be 10 or 14 years? We will wrestle with this question as we design future studies.

Walsh: Chest-wall compliance seems to be different between children and adults, but you didn't mention anything about measuring transpulmonary pressure.

Cheifetz: That is important, but I promised I would stick to my 30 -minute time limit. It comes back to the physiologic differences based on age. Chest-wall compliance is an important variable if you are studying compliance changes in a PEEP study.
Myers: In Colorado about 7 years ago, some of us raised these same questions. I think it's just the lack of funding that's preventing the multicenter pediatric trials we need. It just can't be done in a single center. The pediatric data from Cannon et $\mathrm{al}^{1}$ was over a decade ago, and they used Servo 300 ventilators. Ventilators and ventilator circuitry have greatly changed over the past decade. Do you think that the scattered $\mathrm{V}_{\mathrm{T}}$ measurements would still be the same today if that study was repeated?

1. Cannon ML, Cornell J, Tripp-Hamel DS, Gentile MA, Hubble CL, Meliones JN, Cheifetz IM. $\mathrm{V}_{\mathrm{T}}$ measurements in infants should be obtained with a pneumotachometer located at the endotracheal tube. Am J Respir Crit Care Med 2000;162(6):21092112.

Cheifetz: We debate that topic in our institution as well. Is the current generation of ventilators, with their improved algorithms, better than their predecessors? In preparing for this presentation, I hated to pull up a 10-yearold study, but I could not find any definitive data in the last 10 years. I think it's extremely important to study that question. In a low- $\mathrm{V}_{\mathrm{T}}$ study in infants and children it would be essential to compare $\mathrm{V}_{\mathrm{T}}$ measurements from the ventilator (with the various algorithms that compensate for ventilator circuit compliance) and $\mathrm{V}_{\mathrm{T}}$ measurements obtained at the endotracheal tube. Although ventilator algorithms are clearly better than 10 years ago, I remain skeptical that any algorithm could be as accurate as measuring the $\mathrm{V}_{\mathrm{T}}$ at the airway. There are too many variables that can change during the course of ventilation, including temperature, humidity, secretions, and airway/circuit adaptors.

Curley: A lot of what you presented is operator-dependent. We know there is wide variation at the bedside. Half of what we think we're doing is even being done, let alone done well. I had one clinical site that had a very high enrollment rate during the mock screening and then went down a lot during the trial. A year later I called them up and asked what was going on. One thing that had changed was that they were using more NIV than ever before, which was preventing kids from being intubated. They were able to support pretty sick kids on NIV, which takes away the entire highversus-low- $\mathrm{V}_{\mathrm{T}}$ question.

As far as outcomes are concerned, it depends on the question. We have ventilator-free days and organ-failurefree days, and we can all agree on an operational definition, but that demands the protocols and good clinicians implementing the protocols. But we also have to do long-term follow-up in our patient population. And when we do follow-up, a 14-year-old is different than a 2-year-old: we use different metrics. Being in an ICU is traumatic for kids and the entire family.

Cheifetz: I completely agree. Our patient populations are so heterogeneous, and the population of any ICU can substantially change over time. You know this as well as anyone. Look how long it took to launch the RESTORE [Randomized Evaluation of Sedation Titration for Respiratory Failure] sedation trial [http://www. restorenetwork.org/default.aspx]. Ibelieve you described an 11-year process. Populations, ICUs, management strategies, et cetera will change over that time frame, so we need to consider such moving targets. We always have to consider the uncontrolled variables.

Willson: On the problem of practice variation, in my unit we have nurses, respiratory therapists, physicians, residents, and fellows all playing with the ventilator. They're not supposed to, but they do, so the practice variation is tremendous. We just completed another surfactant study, and there was a protocol, but I'm not sure it made any difference in terms 
of outcomes and how patients were managed.

Before we address any of these questions, my plea would be to get it down to an adequately explicit methodology. Let's put it on a computer. Let's allow people to make ventilator adjustments but require that they justify what they did. Phillipe Jouvet, in the Department of Pediatrics at University of Montreal, started with a simple computer protocol that sits next to the ventilator, and every time you make an adjustment you have to justify why you did it. Before we do anything else, that has to be done, because we don't even begin to understand the practice variation that's involved.

Rubin: I'm going to take up your challenge. You threw down the gauntlet that if something has no proven benefit but it appears to be safe, why shouldn't we use it? I would argue vigorously that there's a very good reason not to do that. First, safety is difficult to test. You gave the example that heliox appears to be safe in all studies, but none of the studies were actually designed to evaluate safety. Just one serious adverse event related to an intervention that has no proven benefit is one too many. We may not identify those rare, adverse events until we look for them and have a large number of patients.

And when you talk about safety, it's not just patient safety, there's a lot of other things that go into this: confounding variables of additional therapies and attribution of benefit when benefit may not exist or may be due to parallel interventions. You can say that heliox is benign, but now I have to think about how we' re giving our aerosol therapy because it's a different viscosity, and how we are adjusting the ventilators. And then there is the additional cost. I would argue strongly against using things without proven value, unless it's within the context of a trial.
Cheifetz: I thought you or Rich [Branson] might take me up on that. I completely respect that view, but I will argue the other side. We simply do not have definitive data, especially in pediatrics, for many therapies in our armamentarium. Should we not offer a therapy that has real potential to help and minimal potential to hurt simply because definitive data are lacking?

Heliox is an example. There have been multiple studies, which I acknowledge were not designed with safety as a primary end point, but, still, none of the studies even hinted at any safety concerns. Thus, we have supportive, but not definitive, data, due to study-power limitations, supportive physics and physiology, and no evidence for safety concerns. So should we not use this therapy when the clinical experience is that at least some patients clearly benefit? Should a clinician withhold such a therapy when the best available information suggests that it is safe and may provide benefit, but it simply has not had the perfect study to prove it?

Consider the simple example of the parachute. ${ }^{1}$ There has never been a prospective randomized controlled trial that demonstrates that a parachute really works, but no one would ever question its effectiveness or safety profile, at least with the respect to what would be the obvious control group.

1. Smith GC, Pell JP. Parachute use to prevent death and major trauma related to gravitational challenge: systematic review of randomised controlled trials. BMJ 2003; 327(7429):1459-1461.

Rubin: Yeah. Do the right study then. If you can identify that subpopulation and you know the benefit clinically, then God bless you and use it. But what is to prevent us from extending it to patients with a variety of diseases just because we don't have data? What's to prevent us from using a whole series of drugs just because? I would argue that the more beneficent way of doing this is that if you're faced with these sorts of decisions, don't just do something: stand there. Stand there and think.

Cheifetz: I could not agree more that as clinicians, when data are lacking, we should stand still for an appropriate amount of time and think before simply acting. Beyond that, if we don't have definitive data, as is often the case, then we must rely on our clinical experience, clinical interpretation, and extrapolation of the available data. I believe we would both agree that this discussion can become very theoretical and could go back and forth many times. ${ }^{1}$ The obvious question is, why not study a subpopulation where a specific therapy seems to work? Well, it comes down to the usual suspects: time, sample size, and funding. As we do not have enough time to fully debate this issue, I would refer the audience to read the excellent paper in which you debated this topic with Ken Steinberg in the proceedings from a prior Journal Conference. ${ }^{1}$

1. Rubin BK, Steinberg KP. When caring for critically ill patients, do clinicians have a responsibility to be innovative and try unproven approaches when accepted approaches are failing? Respir Care 2007; 52(4):408-413; discussion 413-415.

Brown: Regarding practice variation at the beside, designing studies, and evaluating techniques, I think something physicians frequently miss in this discussion is the complexity of modern ventilators and how many adjustments the respiratory therapist can make that are not physician-ordered variables, and how dramatically your ventilation and oxygenation can change after making those changes. It's quite profound. I think when we design a study to evaluate what ventilator settings they were on, we really have little idea what ventilator settings they were on.

Cheifetz: You are absolutely correct. With a modern ventilator the respiratory therapist can essentially 
change what a mode is doing (or even functionally change between modes) by using sub-menus and advanced options and settings to sculpt the breaths. They can change almost everything about a breath without the changes being controlled by protocols or physician order.

Curley: I think we can do this, because if we could agree about what we know right now, and everyone could agree in principle how on to ventilate a patient, as new therapies are developed we could systematically evaluate them. I think that the PALISI Network could, if given a minimum data set and point prevalence surveys, describe and monitor what people are actually doing. Given the electronic case report forms, it doesn't take a lot of information. We typically want every data element on every patient, which requires a lot of time and money, but in reality I think we could do more by forming networks, agreeing what the floor is, practicing the floor, and doing minimum data capture to test whether different things work in subpopulations where it makes sense.

Cheifetz: I could not agree more. Absolutely.

Gentile: Going back to adults versus pediatric patients, the ARDS Network is a clear demonstration of how progress is made. After the positive low- $\mathrm{V}_{\mathrm{T}}$ trial, everybody ran to the ventilator and turned the knob to the left, but $\mathrm{V}_{\mathrm{T}}$ is based on predicted body weight, and we are all getting bigger, including kids. You pointed out that volume controlled continuous mandatory ventilation can be very uncomfortable. And the ICU sedation, analgesia, and delirium clinical trials showed that we should let patients breathe spontaneously. Volume controlled continuous mandatory ventilation at $6 \mathrm{~mL} / \mathrm{kg}$ predicted body weight is lung-protective, but what happens when the patient breathes on their own? If we simply put an endotra- cheal tube in and let someone breathe, the $V_{T}$ can't be controlled or limited, except with sedation.

Cheifetz: Good point. In pediatrics we should not strive to reinvent the wheel. We should base future clinical mechanical ventilation trials on what is already known, often from neonatal and adult patients, learn from the experience of others, and then extrapolate. I think your comment is important.

Gentile: Martha [Curley] touched on patients managed with NIV. Many ICU-based mechanical ventilation trials are now having problems meeting enrollment goals because those patients are now on NIV, and not in the ICU, which leaves the ultra-sick patients in the ICU, who tend to meet the exclusion criteria for various reasons.

Cheifetz: NIV in pediatrics is a huge challenge. Not only do you have the same issues as in adults, but you have the additional issue of interfaces for our various sizes of patient, plus a lack of FDA-approved devices.

Curley: Regarding clinician adherence to protocols, the reason we did the prone-positioning study is that we thought there would be differences in kids. But we ended up stopping the trial. I know we're not supposed to talk about post-hoc analysis, but there was an improved mortality in kids who were better, as compared to the findings of Gattinoni, who found better outcomes in worse patients. There might be a difference in pediatric patients based on physiology. I think we have to continue to ask questions specific to pediatrics, where they make sense.

Walsh: Can we translate some adult medicine studies to pediatrics? One of the classic indicators of ARDS is a $\mathrm{P}_{\mathrm{aO}_{2}} / \mathrm{F}_{\mathrm{IO}_{2}}$ of $<200 \mathrm{~mm} \mathrm{Hg}$. Many of our kids probably have a lower $\mathrm{P}_{\mathrm{aO}_{2}}$ '
$\mathrm{F}_{\mathrm{IO}_{2}}$, and we just don't know about it because they typically don't have an arterial line, the typical indication for which is hemodynamic instability, not gas exchange. When using an $\mathrm{S}_{\mathrm{pO}_{2}}$ / $\mathrm{F}_{\mathrm{IO}_{2}}$ of $<235 \mathrm{~mm} \mathrm{Hg}$ to identify patients, I was surprised that there were a lot of patients who would have met the ARDS criteria if we had arterial blood gas values.

Cheifetz: The use of arterial lines in the PICU settings seems to vary over time. There are data ${ }^{1,2}$ that have validated the use of $\mathrm{S}_{\mathrm{pO}_{2}} / \mathrm{F}_{\mathrm{IO}_{2}}$, but I'm not sure how much $\mathrm{S}_{\mathrm{pO}_{2}} / \mathrm{F}_{\mathrm{IO}_{2}}$ has caught on in standard clinical practice. Is it reasonable to design a low- $\mathrm{V}_{\mathrm{T}}$ study using the $\mathrm{S}_{\mathrm{pO}_{2}} / \mathrm{F}_{\mathrm{IO}_{2}}$ as an entry criterion, and would we have buy-in from clinicians? I don't know. Would you accept a clinical ARDS study using $\mathrm{S}_{\mathrm{pO}_{2}} / \mathrm{F}_{\mathrm{IO}_{2}}$ as either an inclusion criteria or a secondary outcome measurement?

1. Thomas JN, Shaffer ML, Willson DF, Shih MC, Curley MA. Defining acute lung disease in children with the oxygenation saturation index. Pediatr Crit Care Med 2010; 11(1):12-17.

2. Khemani RG, Patel NR, Bart RD III, Newth CJL. Comparison of the pulse oximetric saturation/fraction of inspired oxygen ratio and the $\mathrm{P}_{\mathrm{aO}_{2}}$ /fraction of inspired oxygen ratio in children. Chest 2009;135(3):662668.

Gentile: As long as the patient is not intubated, yes. But the oxygenation index is a much clearer indication of lung impairment, because a pressure cost of oxygenation is reflected in the specific amount of ventilator support. This is one of the things that was developed in pediatrics but is used with increasing frequency in adults. I think it's very important to obtain the oxygenation index, because if the patient is on a PEEP of $5 \mathrm{~cm} \mathrm{H}_{2} \mathrm{O}$, compared to a PEEP of $20 \mathrm{~cm} \mathrm{H}_{2} \mathrm{O}$, there's a huge difference in severity of lung injury that's not reflected in $\mathrm{P}_{\mathrm{aO}_{2}} / \mathrm{F}_{\mathrm{IO}_{2}}$. 
Willson: I love the idea of using noninvasive measurements, and indeed we do. We've seen a tremendous drop in the number of arterial lines. The problem with the surfactant study was that people insisted that $\mathrm{S}_{\mathrm{pO}_{2}}$ had to be $100 \%$ or they're just not comfortable. Of course when you then use the $\mathrm{S}_{\mathrm{pO}_{2}} / \mathrm{F}_{\mathrm{IO}_{2}}$-and you can do the same with the oxygenation index, substituting saturation for $\mathrm{P}_{\mathrm{aO}_{2}}$ - but it's only reliable if the $\mathrm{S}_{\mathrm{PO}_{2}}$ values are in the range of $90-96 \%$. It's really discouraging when people have agreed to use the saturation rather than the $\mathrm{P}_{\mathrm{aO}_{2}}$ but tend to keep patients $100 \%$ saturated. It's a constant battle.

Unfortunately, in our study, where we're looking back at the data, I dare say that over half of the $\mathrm{S}_{\mathrm{pO}_{2}}$ values are $100 \%$, and calculating a saturation index or a saturation ratio doesn't make any sense. Good conceptually, but until we get people to turn down the $\mathrm{F}_{\mathrm{IO}_{2}}$ so $\mathrm{S}_{\mathrm{pO}_{2}}$ is $90-96 \%$, then using $\mathrm{S}_{\mathrm{pO}_{2}}$ rather than $\mathrm{P}_{\mathrm{aO}}$ is just not going to work.

Cheifetz: Finally, I want to ask you this question. Can we study low $V_{T}$ in infants and children? Do you believe we have sufficient equipoise? Could we successfully complete that study? Most of us would probably agree that we should do such a study, but can we? Is it realistic? From the show of hands, it is a 50/50 split.

Rubin: Well, it's not just yes or no. It's yes, no, or it depends on study design. If you're doing $6 \mathrm{~cm} \mathrm{H}_{2} \mathrm{O}$ versus $12 \mathrm{~cm} \mathrm{H}_{2} \mathrm{O}$, the answer is no. If you're doing $4 \quad \mathrm{~cm} \quad \mathrm{H}_{2} \mathrm{O}$ versus $8 \mathrm{~cm} \mathrm{H}_{2} \mathrm{O}$, the answer is perhaps.

Cheifetz: Agreed. So please answer the question assuming the study would be designed exactly how you personally believe it should be. I realize that there are many variables, but if you have the right study group, should this study be attempted, and can it be successfully completed? With this clarification, who believes that such a study is doable? Still about half: maybe slightly more than half.

What about PEEP? Should we? Could we? Same assumptions: with the right algorithms and a protocol that you would accept, can/should we do a PEEP trial in pediatrics? A little less, about one third are raising their hands.

This article is approved for Continuing Respiratory Care Education credit. For information and to obtain your CRCE

(free to AARC members) visit

www.RCJournal.com 